\title{
Gender Differences in Perceptive Emotional Adjustment of Parents on Their Children's Emotional Intelligence
}

\author{
M. T. Sánchez-Núñez ${ }^{1 *}$, C. Rubio Medina1, N. García Rubio² \\ ${ }^{1}$ Faculty of Education, Department of Psychology, University of Castilla La Mancha, Albacete, Spain \\ ${ }^{2}$ Department of Economics and Statistics, University of Castilla La Mancha, Albacete, Spain \\ Email: *mtrinidad.sanchez@uclm.es
}

How to cite this paper: Sánchez-Núñez, M. T., Medina, C. R., \& Rubio, N. G. (2018). Gender Differences in Perceptive Emotional Adjustment of Parents on Their Children's Emotional Intelligence. Psychology, 9, 124-143.

https://doi.org/10.4236/psych.2018.91009

Received: November 20, 2017

Accepted: January 27, 2018

Published: January 30, 2018

Copyright $\odot 2018$ by authors and Scientific Research Publishing Inc. This work is licensed under the Creative Commons Attribution International License (CC BY 4.0).

http://creativecommons.org/licenses/by/4.0/

\begin{abstract}
In the field of intelligence, parental beliefs about their children's intelligence can influence their performance (Beyer, 1999). In a particular way, this phenomenon is known as the Pygmalion effect (Furnham \& Bunclark, 2006). In the area of Emotional Intelligence (EI), the research is scarce. Therefore, our objective is to study if the perceptive emotional adjustment differs according to the sex of the parents, and also to examine if this is reflected in the predictive power of the EI of the children. The sample consisted of 1005 subjects, including 335 students from the University of Castilla la Mancha and their respective fathers and mothers. According to the results of this study, we can conclude that emotional abilities of children perceived by their parents are quite close to those provided by children themselves. However, the mothers, in particular, were able to report these EI abilities more closely, showing, in comparison to fathers, a more accurate emotional adjustment with relation to their children's EI. The prediction of the EI of children varies according to the EI factor we are referring to, as well as with the sex of the parents.
\end{abstract}

\section{Keywords}

Self-Report Emotional Intelligence, Gender Differences, Perceptive Emotional Adjustment, Parents, Children

\section{Introduction}

The family is considered the most important context for emotional literacy in children and the parents are the primarily responsible agents in teaching their children emotional competences (Darling \& Steinberg, 1993; Morris, Silk, Stein- 
berg, Myers, \& Robinson, 2007; Palomera, 2009). As well, parents who are sensitive to the emotional needs of their children, showing them empathy and regulating their emotions, help them to develop those same skills on themselves, boosting their EI (Eisenberg, 1998; Salovey, Bedell, Detweiler, \& Mayer, 2000; Sunew, 2004; Zeidner, Matthews, Roberts, \& MacCann, 2003).

Emotional Intelligence includes the ability to engage in sophisticated information processing about one's own and others' emotions and the ability to use this information as a guide to thinking and behavior. That is, individuals with high EI pay attention to, use, understand, and manage emotions, and these skills provide adaptive functions that potentially benefit themselves and others (Mayer, Salovey, \& Caruso, 2008). The socialization pathways of EI can be direct or indirect (Zeidner et al., 2003):

a) Direct effect route: research has shown that explicit rules given by the parents to their children about how they should express and regulate emotions are important factors for the emotional development of children and their relationships with peers (Gottman, 1997; Rothbart \& Derryberry, 1981; Thompson, 1998). In the same way, it is confirmed that the existence of frequent dialogues between mothers and children about emotions, improves knowledge and emotional understanding of children (Brown \& Dunn, 1996; Denham, 1998; Denham, Zoller, \& Couchoud, 1994; Shipman \& Zeman, 1999).

b) Indirect effect route: On the other hand, studies report that children can learn these emotional skills from their parents indirectly, observing and imitating their behavior in an unconscious way (Matthews, Zeidner, \& Roberts, 2002; Zeidner et al., 2003). In fact, observing the behavior of parents in a given environment, as well as the reactions of the parents to the emotions manifested by their children, offers the child an important source of knowledge about what is appropriate or inappropriate in a particular cultural and social environment (Denham \& Grout, 1993). It has been found that the way how parents express and regulate their emotions influences how children attend and regulate their own (Marsland \& Likavec, 2003; Mayer \& Salovey, 1997). As well, it is confirmed that empathy that children perceive in their parents influences the development of their own empathy and emotional regulation, acting as a background to pro-social behavior (Richaud, 2009). On the other hand, expectations that parents have and communicate, consciously or unconsciously to their children can affect their own development (Furnham \& Bunclark, 2006).

In the field of intelligence, parental beliefs about the intelligence of their children, although they are not closely related to a real capacity may have adverse behavioral and cognitive effects, making children behave as expected of them (Beyer, 1999). This phenomenon is known as Pygmalion effect (Furnham \& Bunclark, 2006). At this respect, studies show that estimates that parents do on the Intelligence Quotient (IQ) of children correlate significantly with the actual scores on IQ of their children, derived from tests on verbal, numerical and perceptual skills, having the mothers, in comparison to the fathers, a more accu- 
rate perception (Furnham \& Bunclark, 2006). In the family setting our own perceptions can have a significant effect. In a study conducted by Furnham et al. on IQ, the parents' estimate of their own intelligence correlated with, and even had predictive power for, their estimate of their children's intelligence (Furnham, Rakow, \& Mack, 2002; Kirkcaldy, Noack, Furnham, \& Siefen, 2007).

If we transfer this result to the field of IE, in this sense, a study found that perceived IE of the parents upon the children predicted the emotional Attention of children (Sánchez-Núñez, Fernández-Berrocal, \& Latorre, 2013). They also found significant associations between the self report EI and the perceived EI between parents and children. That is, the estimates parents have of their own EI correlate with the perception they have of their children's and the same is true for the children in relation to their parents.

However, it would be interesting to investigate whether perceptive emotional adjustment differs according to the gender of parents and whether these differences are also reflected in the predictive power on self-reported EI (SEI) of the children.

\section{Emotional Intelligence and Gender}

Some evidence exists that certain areas of the brain dedicated to processing emotions could be larger in women than in men (Baron-Cohen, 2003, 2005; Gur, Gunning-Dixon, Bilker, \& Gur, 2002) and that there is a difference in the brain activity based on gender (Jaušovec \& Jaušovec, 2005; Castro-Schilo \& Kee, 2010). However, inequality in patterns of emotional behavior of men and women is influenced greatly by gender stereotypes. In Spain, Gartzia, Aritzeta, Balluerka and Barberá (2012) demonstrated that women and men who show a less stereotyped type of identity show higher levels of EI than people with a gender identity type more in line with their gender. Since identification with such traits derives from mental representations about gender and are directly related to gender stereotypes, the existence of gender stereotypes in relation to EI competences may also be an underlying explanation of gender differences in EI.

The scientific literature on gender differences regarding emotional skills has emphasized that women recognize other people's emotions better, are more perceptive, scored higher in appraisal of emotions, are more expressive than men and have greater empathy (Argyle, 1990; Sánchez-Núñez, Fernández-Berrocal, Montañés, \& Latorre, 2008; Hargie, Saunders, \& Dickson, 1995; Shin, 2011) while males scored better in factor of utilization on emotion (Shi \& Wang, 2007).

The Trait Meta Mood Scale (TMMS) constitutes one of the most widely used self-report in Spanish-speaking population and provides widely known instruments to measure perceived EI under the Mayer and Salovey's paradigm (Salovey et al., 1995). It measures the perception of attention to emotion, emotional clarity and emotional repair. These findings suggest that, although research about gender differences is inconsistent and unclear, there are some EI dimensions in which women seem to show particularly high scores (i.e., those related 
to emotion perception and understanding), whereas gender differences are less pronounced, or even sometimes might favor men, in those EI dimensions that are related to the handling and repair of one's emotions (Gartzia \& López-Zafra, 2014; Sánchez-Núñez et al., 2008).

These results support studies showing how women are socialized to be more empathetic than men, both in form of capturing feelings in the face and voice, and other nonverbal messages; and, in the case of men, to avoid expressing emotions that are related to guilt, vulnerability, fear or pain (Brody \& Hall, 1993; McClure, 2000; Rosenthal, Hall, DiMatteo, Rogers, \& Archer, 1979). Some studies have shown how these differences are also perceived by others. In this sense, the study conducted by Shin (2011) showed how college students perceived men with more emotional intelligence, especially, in factors related to the management of emotions and the ability to handle conflicts in a rational and logical way. Moreover, women were perceived with a greater degree of emotionality and emotional expression, which made them more sensitive to emotions.

We have considered gender differences in IE and the importance of socialization indirect pathways EI, highlighting the perception of parents about their children's EI. Our interest is focused on an unexplored area to date. For a better comprehension of the study and the reading of the analysis we have interpreted the term Self-informed emotional intelligence (SEI), as the individual's perception of their own EI, measured by the TMMS-24, in order to differentiate it from the Perceived Emotional Intelligence (PEI) which is interpreted as how a family member perceives another family member's EI, measured by the PTMMS-24. Our goal is to focus on gender differences in SEI and PEI in the family, in particular, in the perceptual adjustment of parents regarding the SEI of their children and how it might influence the children SEI. To carry out this study we propose the following research objectives:

- Analyze if there are gender differences in IE in the SEI for the children, as in PEI by their parents.

- Analyze the degree of perceptual emotional adjustment of parents over their children, and check if mothers have higher perceptual adjustment than parents.

- Analyze the influence of the parents PEI about their children in the SEI of children.

Therefore, and depending on the objectives, we study the following hypothesis:

1) There are significant differences in the children's SEI in the TMMS-24 with higher scores of daughters in emotional Attention and sons in emotional Repair.

2) There are significant differences in the parents' PEI about their children with higher scores of daughters in emotional Attention and sons in emotional Repair.

3) There is a positive significant correlation between parents' PEI evaluated through PTMMS-24 and the children's SEI evaluated through TMMS-24, being 
the mothers who show a higher significant correlation with children's SEI.

4) The children's SEI evaluated through TMMS-24 in Attention, Clarity and Repair can be explained by the parent's PEI of their children evaluated through PTMMS-24.

\section{Method}

\subsection{Participants}

The original sample comprised 335 students at the University of Castilla-La Mancha who still lived in the family home and their respective fathers and mothers. 1005 subjects in the total sample, completed the evaluation tests. The mean age of parents is $\mathrm{M}=50, \mathrm{SD}=4.93$ and for children $\mathrm{M}=21.78, \mathrm{SD}=2.04$. The age range of parents is between 40 and 64 being $18-29$ years in the case of children. All family members lived in the same family home and the participation was voluntary. The families in the sample have a medium socioeconomic level and do not present significant differences in their sociodemographic conditions.

\subsection{Measures}

Trait Meta-Mood Scale-24 (TMMS-24; Fernández-Berrocal, Extremera, \& Ramos, 2004). This scale is an adaptation of the original one of Salovey et al. (1995) "Trait-Meta Mood Scale-48" (TMMS-48) to try to make the concept of EI being operative. This scale comprised 24 items and provides an indicator of the subject's perceived EI level. The subjects are required to indicate their level of agreement with each item on a five-point Likert type scale from Strongly disagree (1) to Strongly agree (5). The scale is made up of three factors or sub-scales: Attention to own feelings, emotional Clarity and Repair of emotions. Attention to emotions, measured through 8 items, means how much attention individuals believe they pay to their inner feelings ("I think about my mood constantly"). Clarity, measured through the next 8 items on the scale, reflects how individuals believe they perceive their emotions ("I am often confused about how I feel"). And Repair, measured by the last 8 items, is the individual's belief about their ability to terminate negative emotions and prolong positive ones ("Although I am sometimes sad I have a mostly optimistic outlook").

A sequential dependence between the components of the EI (Attention, Clarity and Repair) has been documented. Emotional Reparation has been predicted by Clarity (Salovey et al., 1995), and both correlate significantly with each other, as well as the Attention and Clarity factors. A person cannot differentiate between emotions if he or she does not first attend to them, and will not be able to repair or manage them effectively unless they know what those emotions are. Persons with a high EI in the Spanish speaking population have a model characterised by moderate to low scores in Attention and high scores in Clarity and Repair (Extremera \& Fernández-Berrocal, 2002; Extremera \& Fernández-Berrocal, 2005). 
The authors of this scale found an internal consistency of .90 for Attention, .90 for Clarity and .86 for Repair. Moreover, it improved the psychometric properties of the longer 48 item version, .86 for Attention, 87 for Clarity and .82 for Repair (Salovey et al., 1995). In this current study, the Cronbach's alphas for each of the TMMS dimensions were suitable ( .88 for Attention; .89 for Clarity and .86 for Repair).

Perceived emotional intelligence scale (PTMMS-24; Sánchez-Núñez, Fernández-Berrocal, \& Latorre, 2013). The PTMMS-24 is a version of the TMMS-24 developed by Fernández-Berrocal et al. (2004) specifically adapted for this study. The PTMMS-24 evaluates the parents' PEI of their children and the children's PEI of their parents in the three factors or sub-scales (Attention to own feelings, emotional Clarity and Repair of emotions). For this reason the 24 items of the scale are written in third person. The parents were asked to think about their son/daughter when scoring the items and the sons/daughters were asked to think about their father/mother. Attention to emotions, measured through 8 items, is how much attention parents believe their children pay to their inner feelings and vice versa ("He/She thinks about his/her mood constantly"). Clarity, measured through the next 8 items on the scale, is how parents believe their children perceive their emotions and vice versa ("He/She is often confused about how he/she feels"). And finally, Repair, measured by the last 8 items, is the parent's belief of the ability of their children to terminate negative emotions and prolong positive ones and the same for the children and their parents ("Although he/she is sometimes sad he/she has a mostly optimistic outlook").

This allows the self-reported measures to be compared with those reported by the rest of the family members on the subject in question. We believe this will provide interesting information on the intrapersonal and interpersonal perception of emotional abilities among family members. The indirect reliability indicator for this scale, measured by Cronbach's Alpha, was satisfactory, with internal consistencies of above .80 for each self-reported EI sub-scale (Attention .86; Clarity .87 and Repair .88). The correlations among the scale factors were as expected. Attention correlated with Clarity $(r=.323, p=.005)$ and the latter with Repair $(r=.364, p=.002)$; however, there was no correlation between Attention and Repair (Sánchez-Núñez, Fernández-Berrocal, \& Latorre, 2013).

\subsection{Statistical Analysis}

The statistical analysis was carried out using the statistical software SPSS 17.0 for Windows. A preliminary and explorative analysis of each variable in this study was conducted. The analysis of extreme values based on Mahalanobois distance led us to discard 20 cases, leaving the final sample consisting of 355 subjects (174 sons and 161 daughters). After it, a correlation analysis was carried out using the Pearson correlation coefficient and a test for mean differences through Student $\mathrm{T}$ test for independent samples. Furthermore, a multiple regression analysis was 
accomplished to study the relationship between each family member's SEI and each family member's PEI on the other members.

\section{Results}

Table 1 shows a summary of descriptive statistics (size, mean, standard deviation and range) for each variable implied in this study. The sample has been divided according to the children's sex.

In relation to the hypotheses 1 and 2, T-tests for independent samples were conducted to analyze the differences between the mean values in SEI and PEI (Attention, Clarity and Repair) by sons and daughters. Homogeneity of variances in male and female subsample was checked through Levene's Test. The results are reported in Table 2. Equal variances could be assumed for all comparisons except for SEI Repair and PEI Repair reported by fathers. So in these

Table 1. Descriptive analysis.

\begin{tabular}{|c|c|c|c|c|c|}
\hline & $\mathbf{N}$ & Mean & S.D. & Min. & Max. \\
\hline \multicolumn{6}{|l|}{ Sons } \\
\hline Age & 174 & 21.89 & 2.15 & 18.00 & 29.00 \\
\hline Attention son & 174 & 3.26 & .72 & 1.75 & 5.00 \\
\hline Clarity son & 174 & 3.43 & .66 & 1.38 & 5.00 \\
\hline Repair son & 174 & 3.51 & .75 & 1.12 & 5.00 \\
\hline Attention father & 174 & 3.20 & .72 & 1.50 & 5.00 \\
\hline Clarity father & 174 & 3.28 & .63 & 1.25 & 4.87 \\
\hline Repair father & 174 & 3.43 & .66 & 2.00 & 4.88 \\
\hline Attention mother & 174 & 3.20 & .76 & 1.38 & 4.88 \\
\hline Clarity mother & 174 & 3.44 & .63 & 2.12 & 5.00 \\
\hline Repair mother & 174 & 3.39 & .75 & 1.75 & 5.00 \\
\hline \multicolumn{6}{|l|}{ Daughters } \\
\hline Age & 161 & 21.76 & 2.44 & 18.00 & 29.00 \\
\hline Attention daughter & 161 & 3.45 & .77 & 1.87 & 4.88 \\
\hline Clarity daughter & 161 & 3.50 & .64 & 2.00 & 5.00 \\
\hline Repair daughter & 161 & 3.24 & .81 & 1.50 & 5.00 \\
\hline Attention father & 161 & 3.40 & .72 & 1.88 & 5.00 \\
\hline Clarity father & 161 & 3.45 & .70 & 1.63 & 5.00 \\
\hline Repair father & 161 & 3.42 & .78 & 1.25 & 5.00 \\
\hline Attention mother & 161 & 3.48 & .76 & 1.00 & 5.00 \\
\hline Clarity mother & 161 & 3.54 & .70 & 1.12 & 4.88 \\
\hline Repair mother & 161 & 3.37 & .76 & 1.25 & 5.00 \\
\hline
\end{tabular}


Table 2. T-test for Equality of SEI and PEI means by gender (sons-daughters).

\begin{tabular}{ccccccc}
\hline & & $\begin{array}{c}\text { Levene's } \\
\text { Test }\end{array}$ & T Test & & $\begin{array}{c}\text { 95\% Confidence Interval } \\
\text { of the Difference }\end{array}$ \\
\hline & & F & $\begin{array}{c}\text { Mean Difference } \\
\text { (sons-daughters) }\end{array}$ & T & Lower & Upper \\
\hline \multirow{3}{*}{ SEI $\quad$ Attention } & 1.43 & -.19 & $-2.35^{*}$ & -.35 & -.03 \\
& Clarity & .00 & -.07 & -.93 & -.21 & .07 \\
& Repair & $4.06^{*}$ & .27 & $3.15^{* *}$ & .10 & .44 \\
& Attention (F) & .03 & -.20 & $-2.53^{*}$ & -.35 & -.04 \\
& Clarity (F) & 3.43 & -.17 & $-2.35^{*}$ & -.31 & -.03 \\
& Repair (F) & $5.44^{*}$ & .02 & .23 & -.14 & .17 \\
& Attention (M) & .01 & -.28 & $-3.38^{* *}$ & -.44 & -.12 \\
& Clarity (M) & 1.09 & -.10 & -1.39 & -.24 & .04 \\
& Repair (M) & .10 & .03 & .33 & -.13 & .19 \\
\hline
\end{tabular}

${ }^{\star} p<.05 ;{ }^{* *} p<.01$; Note: Equal variances are assumed except for SEI Repair and PEI Repair F. F = Father; $\mathrm{M}=$ Mother.

cases $\mathrm{T}$-tests for independent samples were conducted without assuming equal variances. T-tests in Table 2 revealed significant gender differences $(p<.05)$ in SEI Attention in favor of daughters $(\mathrm{M}=3.45, \mathrm{SD}=.77)$ against sons $(\mathrm{M}=3.26$, $\mathrm{SD}=.72)$. The test also revealed a significant mean difference $(p<.01)$ in SEI Repair, but in this case with the sons $(\mathrm{M}=3.51, \mathrm{SD}=.75)$ showing a higher value than daughters $(\mathrm{M}=3.24, \mathrm{SD}=.81)$. With regard to PEI, T-tests revealed significant differences in Attention, both in the reported by fathers or mothers, in favor of daughters. A similar result was found for PEI Clarity, but in this case only when reported by fathers.

In relation to the hypothesis 3 , in order to analyze who (fathers or mothers) show a higher correlation with their children and to study if results are valid for both male and female subsamples, $t$-tests for differences between dependent correlations have been carried out (Table 3 ). First of all, the correlation for every variable between father and mother $(r F / M)$ is significant with $p<.01$. Focusing on Attention, mothers seem to fit better than fathers with their children; however this difference is not significant $(p=.47)$. Nevertheless, splitting results by gender, in the case of daughters the t-test revealed a higher and significant difference favoring mothers, which means a better understanding between mothers and daughters. There are also significant differences favoring mothers in Clarity $(p=.01)$ and Repair $(p=.04)$ if the whole sample is taken into account, although the reasons may be quite different. In the case of Clarity, the strongest difference is provided by a different relation of mothers/fathers with sons $(p=.00)$, while in the case of Repair, differences come from the relation with daughters ( $p$ $=.07)$.

Table 4 shows the correlation coefficients for each pair of variables in the study. Results reveal that in most cases the correlation between what is perceived 
Table 3. Differences in Correlations between TMMS-24 and PTMMS-24 (father-children/ mother-children).

\begin{tabular}{ccccccc}
\hline & \multicolumn{4}{c}{ PTMMS-24 } & \multicolumn{2}{c}{ Differences F-M } \\
\hline \multirow{2}{*}{ TMMS-24 } & & Father & Mother & r F/M & $\mathrm{t}$ & $\mathrm{P}$ \\
\hline \multirow{3}{*}{ Children } & Attention & $.38^{* *}$ & $.42^{* *}$ & $.57^{* *}$ & -.72 & .47 \\
& Clarity & $.18^{*}$ & $.33^{* *}$ & $.41^{* *}$ & $-2.60^{* *}$ & .01 \\
& Repair & $.29^{* *}$ & $.40^{* *}$ & $.46^{* *}$ & $-2.06^{*}$ & .04 \\
& Attention & $.39^{* *}$ & $.32^{* *}$ & $.51^{* *}$ & .99 & .32 \\
\multirow{3}{*}{ Sons } & Clarity & .01 & $.34^{* *}$ & $.36^{* *}$ & $-3.08^{* *}$ & .00 \\
& Repair & $.32^{* *}$ & $.41^{* *}$ & $.44^{* *}$ & -1.00 & .32 \\
& Attention & $.36^{* *}$ & $.49^{* *}$ & $.61^{* *}$ & $-2.17^{*}$ & .03 \\
& Clarity & $.27^{* *}$ & $.31^{* *}$ & $.44^{* *}$ & -.57 & .57 \\
& Raughters & $.27^{* *}$ & $.40^{* *}$ & $.48^{* *}$ & -1.84 & .07 \\
\hline
\end{tabular}

t: t-test for differences between dependent correlations. ${ }^{*} p<.05 ;{ }^{* *} p<.01$.

Table 4. Correlation (above diagonal) and partial correlation (below diagonal) coefficients.

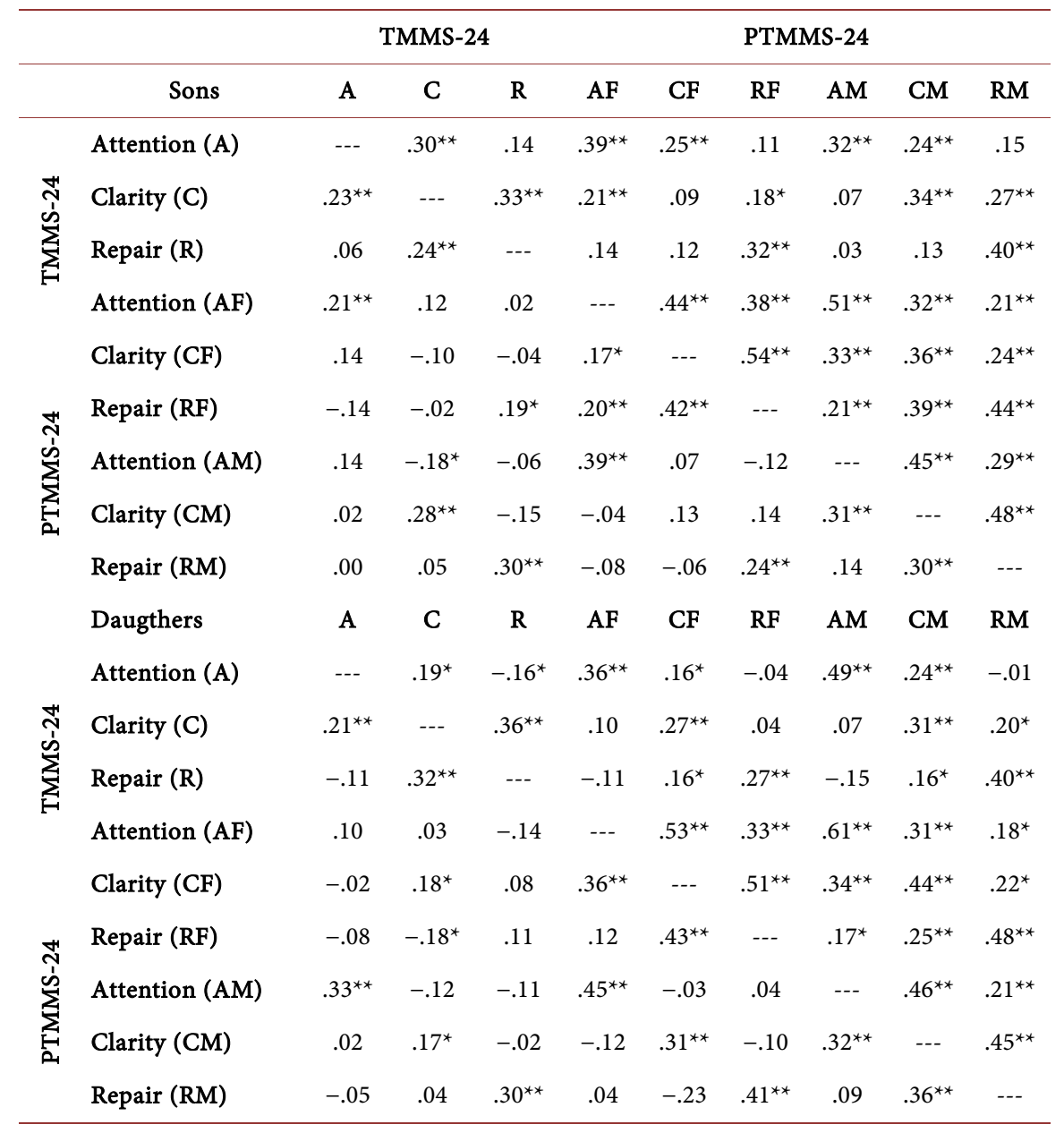

${ }^{*} p<.05 ;{ }^{* *} p<.01$. Note: $\mathrm{F}=$ Father; $\mathrm{M}=$ Mother. 
by the father and the mother about their child is stronger than the correlations mother-child or father-child.

In relation to the hypothesis 4 , Table 5 reports the results of the regression analysis to explain Attention from TMMS-24 based on the other two self-report emotional intelligence variables from TMMS-24 and the six variables of emotional intelligence perceived by parents (fathers and mothers) from PTMMS-24. Starting with the male subsample (sons), a significant regression equation was found $(\mathrm{F}(8,165)=6.72, p<.00)$ with and adjusted $\mathrm{R}^{2}$ of .21 . Only two independent variables revealed to be significant (self-reported Clarity and the Attention perceived by the father) both with a positive coefficient and $p<.01$. Neither Clarity reported by the father nor the reported by the mother were significant regressors. This may be largely due to the low partial correlation that these variables, especially Clarity perceived by the mother, show with the dependent variable; which, in turn, can be explained by the correlation between these variables and the only PTMMS-24 significant variable in the model: Attention perceived by the father. Multicollinearity problems for the variables used in the regression analysis were discarded after observing moderated variance inflation factors (VIFs) in the range from 1.30 to 1.81 . On the other hand, the Durbin-Watson (D-W) value (1.72) approximately equal to 2 indicates no serial correlation among residuals.

For the female subsample, a significant regression equation was found $(\mathrm{F}(8,152)=8.31, p<.00)$ with and adjusted $\mathrm{R}^{2}$ of .27 . In this case only self-reported Clarity and Attention perceived by the mother revealed as significant, again with positive regression coefficients and $i<.01$. The Attention perceived by the mother is the only variable that shows a significant partial correlation

Table 5. Regression analysis. Dependent variable TMMS-24 (Attention); Independent variables: TMMS-24 (Clarity and Repair) and PTMMS-24 (Attention, Clarity and Repair perceived by father and mother).

\begin{tabular}{ccccccccc}
\hline & \multicolumn{3}{c}{ Sons } & & \multicolumn{3}{c}{ Daughters } \\
\hline & B & SE & $\beta$ & & B & SE & $\beta$ \\
\hline $\mathbf{R}^{2}=.21 \mathrm{DW}=1.72$ & & & & $\mathrm{R}^{2}=.27 \mathrm{DW}=1.82$ & & & \\
Intercept & $.91^{*}$ & .41 & & Intercept & $1.55^{*}$ & .43 & \\
Clarity & $.25^{* *}$ & .08 & $.23^{* *}$ & Clarity & $.25^{* *}$ & .09 & $.21^{* *}$ \\
Repair & .06 & .08 & .06 & Repair & -.11 & .08 & -.12 \\
Attention (F) & $.24^{* *}$ & .09 & $.24^{* *}$ & Attention (F) & .13 & .10 & .12 \\
Attention (M) & .15 & .08 & .15 & Attention (M) & $.42^{* *}$ & .10 & $.41^{* *}$ \\
Clarity (F) & .17 & .10 & .16 & Clarity (F) & -.03 & .11 & -.03 \\
Clarity (M) & .02 & .10 & .01 & Clarity (M) & .02 & .10 & .02 \\
Repair (F) & -.18 & .10 & -.15 & Repair (F) & -.09 & .09 & -.09 \\
Repair (M) & -.00 & .08 & -.01 & Repair (M) & -.06 & .09 & -.06 \\
\hline
\end{tabular}

${ }^{*} p<.05 ;{ }^{* *} p<.01$. Note: $\mathrm{F}=$ Father; $\mathrm{M}=$ Mother. 
with the dependent variable in the model while Attention perceived by the father was not significant due to the high correlation that shows with the former one. Something similar happens with the Clarity perceived by the mother, which also shows a significant correlation with Attention perceived by the mother. Again, no problems relating to multicollinearity or autocorrelation have been detected.

Table 6 reports the results of the regression analysis to explain Clarity from TMMS-24 based on the other two self-report emotional intelligence variables from TMMS-24 and the six variables of emotional intelligence perceived by parents (fathers and mothers) from PTMMS-24. For the male subsample (sons), a significant regression equation was found $(\mathrm{F}(8,165)=7.57, p<.00)$ with and adjusted $\mathrm{R}^{2}$ of .23 . The significant predictors were the self-reported Attention and Repair and the Attention and Clarity reported by the mother. All coefficients showed positive signs except from the Attention perceived by the mother. VIFs ranging from 1.26 to 1.84 indicated that there were no problems concerning multicollinearity while a D-W slightly below 2 did not suggest correlated residuals.

For the female subsample (daughters), a significant regression equation was found $(\mathrm{F}(8,152)=7.27, p<.00)$ with and adjusted $\mathrm{R}^{2}$ of .24 . The significant regressors were the self-reported Attention and Repair and Clarity reported both by the father and the mother in a direct way. On the other hand, Repair reported by the father showed a significant and inverse influence on the self-reported Clarity of daughters. In order to analyze if this behavior is conditioned by cases where Repair reported by the father was extremely high or "excellent", a new regression model was conducted removing those cases with Repair (F) above 4.5. Results, displayed in Table 7, showed that the variable Repair reported by the father was no longer significant after eliminating extreme cases.

Table 6. Regression analysis. Dependent variable TMMS-24 (Clarity); Independent variables: TMMS-24 (Attention and Repair) and PTMMS-24 (Attention, Clarity and Repair reported by father and mother).

\begin{tabular}{ccccccccc}
\hline & \multicolumn{3}{c}{ Sons } & & \multicolumn{3}{c}{ Daughters } \\
\hline & B & SE & $\beta$ & & B & SE & $\beta$ \\
\hline $\mathbf{R}^{2}=.23 \mathrm{DW}=1.66$ & & & & $\mathbf{R}^{2}=.24 \mathrm{DW}=1.85$ & & & \\
Intercept & $1.32^{* *}$ & .35 & & Intercept & $1.47^{* *}$ & .36 & \\
Attention & $.21^{* *}$ & .07 & $.22^{\star *}$ & Attention & $.18^{* *}$ & .07 & $.21^{* *}$ \\
Repair & $.21^{* *}$ & .07 & $.24^{* *}$ & Repair & $.27^{* *}$ & .06 & $.34^{* *}$ \\
Attention (F) & .12 & .08 & .13 & Attention (F) & .03 & .09 & .03 \\
Attention (M) & $-.17^{*}$ & .07 & $-.19^{*}$ & Attention (M) & -.13 & .09 & -.15 \\
Clarity (F) & -.11 & .09 & -.11 & Clarity (F) & $.20^{*}$ & .09 & $.22^{*}$ \\
Clarity (M) & $.33^{* *}$ & .09 & $.32^{\star *}$ & Clarity (M) & $.18^{*}$ & .09 & $.20^{*}$ \\
Repair (F) & -.02 & .09 & -.02 & Repair (F) & $-.17^{*}$ & .08 & $-.21^{*}$ \\
Repair (M) & .05 & .08 & .06 & Repair (M) & .04 & .08 & .05 \\
\hline
\end{tabular}

${ }^{\star} p<.05 ;{ }^{* *} p<.01$. Note: $\mathrm{F}=$ Father; $\mathrm{M}=$ Mother. 
Finally, two regression models were carried out to explain the self-reported Repair (Table 8). For the male sub-sample, the model $(\mathrm{F}(8,165)=7.38, p<.00)$ overall explained $23 \%$ of the total variance of the dependent variable whereas for the female group, the percentage of explained variance in terms of the adjusted $\mathrm{R}^{2}$ reached $31 \%(\mathrm{~F}(8,152)=9.79, p<.00)$. Self-reported Clarity and Repair reported by the mother were significant predictors (with positive sign) in both models. Repair reported by the father only remained significant explaining the

Table 7. Regression analysis. Dependent variable TMMS-24 (Clarity); Independent variables: TMMS-24 (Attention and Repair) and PTMMS-24 (Attention, Clarity and Repair reported by father and mother).

Cases with Repair $(F)>4.5$ have been excluded from the female sample

\begin{tabular}{cccc}
\hline Daughters & B & SE & $\beta$ \\
\hline $\mathrm{R}^{2}=.24$ DW $=1.84$ & & & \\
Intercept & $1.46^{* *}$ & .39 & $.22^{*}$ \\
Attention & $.18^{*}$ & .07 & $.33^{* *}$ \\
Repair & $.26^{* *}$ & .07 & .00 \\
Attention (F) & .00 & .09 & -.17 \\
Attention (M) & -.15 & .09 & $.22^{*}$ \\
Clarity (F) & $.20^{*}$ & .09 & $.23^{\star}$ \\
Clarity (M) & $.21^{*}$ & .09 & -.16 \\
Repair (F) & -.14 & .08 & .05 \\
Repair (M) & .05 & .08 & \\
\hline
\end{tabular}

${ }^{\star} p<.05 ;{ }^{* *} p<.01$. Note: $\mathrm{F}=$ Father; $\mathrm{M}=$ Mother.

Table 8. Regression analysis. Dependent variable TMMS-24 (Repair); Independent variables: TMMS-24 (Attention and Clarity) and PTMMS-24 (Attention, Clarity and Repair reported by father and mother).

\begin{tabular}{ccccccccc}
\hline & \multicolumn{3}{c}{ Sons } & & \multicolumn{3}{c}{ Daughters } \\
\hline & B & SE & $\beta$ & & B & SE & $\beta$ \\
\hline $\mathrm{R}^{2}=.23 \mathrm{DW}=2.12$ & & & & $\mathrm{R}^{2}=.31 \mathrm{DW}=1.95$ & & & \\
Intercept & $1.38^{*}$ & .41 & & Intercept & $1.45^{*}$ & .44 & \\
Attention & .06 & .08 & & Attention & -.12 & .08 & -.11 \\
Clarity & $.27^{* *}$ & .09 & $.24^{* *}$ & Clarity & $.39^{* *}$ & .09 & $.31^{* *}$ \\
Attention (F) & .02 & .09 & .02 & Attention (F) & -.19 & .11 & -.17 \\
Attention (M) & -.07 & .09 & -.07 & Attention (M) & -.13 & .10 & -.13 \\
Clarity (F) & -.05 & .10 & -.04 & Clarity (F) & .11 & .11 & .10 \\
Clarity (M) & -.20 & .10 & -.17 & Clarity (M) & -.02 & .10 & -.02 \\
Repair (F) & $.26^{*}$ & .10 & $.22^{*}$ & Repair (F) & .13 & .09 & .12 \\
Repair (M) & $.33^{* *}$ & .02 & $.33^{* *}$ & Repair (M) & $.35^{* *}$ & .09 & $.33^{* *}$ \\
\hline
\end{tabular}

${ }^{*} p<.05 ;{ }^{*} p<.01$. Note: $\mathrm{F}=$ Father; $\mathrm{M}=$ Mother. 
self-reported Repair of sons while in the case of daughters, the coefficient was not statistically different from zero because neither was the partial correlation. The explanation can be found in the important correlation between this predictor and the Repair reported by the mother which was a very relevant predictor in the model.

In both cases (male and female groups) moderated values of VIFs and a value of $\mathrm{D}$-W near 2 did not suggest serious problems related to multicollinearity or autocorrelation.

\section{Discussion}

The first hypothesis of our study "There are significant differences in the children's SEI in the TMMS-24 with higher scores of daughters in emotional Attention and sons in emotional Repair" is confirmed. These results corroborate the data provided by previous research in which women in TMMS showed particularly high scores in emotion perception and understanding, and men in those EI dimensions that are related to the handling and repair of one's emotions (Gartzia \& López-Zafra, 2014; Sánchez-Núñez et al., 2008). Possibly the origin of these differences can be explained in part due to a differential instruction in both sexes at an early age, based on the education of girls focused on emotional expression and identification (Argyle, 1990; Hargie et al., 1995) and the education of children based on problem solving (Fivush et al., 2000; Jones et al., 2002). However, these results place daughters at a disadvantage against male children in SEI, because a high emotional Attention combined with low emotional Repair disclose a low profile IE. That is, excessive attention, without appropriate Clarity and Repair, can lead to a ruminative process of emotional misunderstanding favorable to maintain a negative emotional state (Extremera \& Fernández-Berrocal, 2006).

Regarding the second hypothesis of the study, "There are significant differences in the parents PEI about their children with higher scores of daughters in emotional Attention and sons in emotional Repair" it only partially supported. The results show significant differences in Attention levels reported from both fathers and mothers with higher values for daughters than sons. Moreover, a similar behavior has been detected in the case of Clarity reported by fathers. However, we found no significant relationships as regards the Repair factor. Perhaps studies that claim the continued development of emotional understanding and regulation in adulthood (Chapman \& Hayslip, 2006; Extremera, Fernández-Berrocal, \& Salovey, 2006; Goldenberg, Matheson, \& Mantler, 2006; Kafetsios, 2004; Van Rooy, Alonso, \& Viswesuaran, 2005), could in some way justify this result. They point out that the ability to attend to and clarify emotions is developed first and later, over time, the emotional regulation is developed. In this case, emotion related abilities could still be in process of development.

Regarding our third hypothesis "There will be a significant correlation be- 
tween parents' PEI evaluated through PTMMS-24 and the children's SEI evaluated through TMMS-24, being mothers who show a higher significant correlation with children's SEP' also it is confirmed. The results show significant correlations in the three factors of the SEI of children (Attention, Clarity and Repair) and the PEI by parents. These data are consistent with research where it shows a good perceptive emotional adjustment of parents about their single children and firstborns (Rubio \& Sánchez-Núñez, 2013). All this confirms that parents have a good knowledge about the emotions of their children based on attention, clarity and regulation they deliver to emotions. In turn, these results confirm a better perceptual adjustment on their children SEI of mothers compared to parents in Clarity and Repair factors. When we consider the sex of the children, we find a better perceptual adjustment of mothers in the case of Clarity emotional factor in sons and the emotional Attention in daughters. These results are consistent with the research that shows that women recognize other people's emotions better, are more perceptive, and have greater empathy (Argyle, 1990; Sánchez-Núñez et al., 2008; Hargie et al., 1995; Shin, 2011). The origin of these differences could be explained by the differential development in emotional education based on gender, where women are socialized to be more empathetic and perceptive than men (Brody \& Hall, 1993; McClure, 2000; Rosenthal et al., 1979).

Regarding our fourth hypothesis, "The children's SEI evaluated through TMMS-24 in Attention, Clarity and Repair can be explained by the parent's PEI of their children evaluated through PTMMS-24", the results depend on EI factor to which we refer or parents' sex. The son's SEI for Attention is in first place predicted by his self-reported Clarity and secondly by the father's PEI in Attention. For daughters the results are similar. The daughter's SEI for Attention is predicted by her self-reported Clarity and secondly by the mother's PEI in Attention. In these results a differential pattern for sons and fathers against daughters and mothers is sight for emotional Attention. Investigate the origin of this model could lead to differential modeling of emotional Attention by sex. Given the differences in the emotional Attention based on gender, these findings could support the hypothesis of modeling where children identify with fathers and daughters with mothers (Fernández-Berrocal et al., 2004; Molero, Álvarez, \& de Ávila, 2010; Morales \& López-Zafra, 2008). On the other hand, these results are consistent with previous studies where the fathers' PEI over children has predictive power on the emotional Attention of children (Sánchez-Núñez et al., 2013).

Regarding the emotional Clarity factor it is explained primarily by the sons' and daughter's SEI in emotional Attention and Repair. Secondly and depending on the sex of children Clarity will be differentially influenced by the parents' PEI about them. Thus in the case of male children it is the mother's PEI in emotional Attention and Clarity that predicts emotional Clarity of her sons. However, in the case of the daughters the emotional Clarity is explained by the mother's PEI in emotional Clarity and parent's PEI in emotional Clarity and Repair. Daughters take into account both the mother and the father in the PEI about them may 
be due, on one hand, to the greatest skill that women shown in this factor capturing the emotional signals and scored higher in appraisal of emotions (Shin, 2011). On the other hand, the fact that in this sample the parents perceive daughters with higher emotional Clarity that sons could mediate these results.

Finally, self-reported emotional Repair by sons and daughters is first explained by self-reported emotional Clarity. Secondly, in the case of sons the father's and mother's PEI about his emotional Repair predicts his self-reported emotional Repair. However, in the case of daughters, only the mother's PEI in emotional Repair predicts the self-reported emotional Repair on daughters. Show that children are influenced by the perception of both parents in emotional Repair it may be mediated by the increased ability than men usually present in this factor (Sánchez-Núñez et al., 2008; Shin, 2011). The perception of parents about their sons in this factor agrees with this tendency although the differences are not statistically significant.

The children's SEI is in the first place predicted by the different SEI factors and secondly by the parent's PEI about their children. This pattern holds in the three factors of EI in our study. These results are complementary to others where the children's PEI about their parents is the highest predictor for the children's SEI, before their own SEI (Sánchez-Núñez et al., 2013).

As limitation or weaknesses of our study, it should be highlighted a possible bias in the representativeness of the sample due to the non-random nature of the sampling process. This fact makes that some caution should be taken into account when it comes to generalize the results. Therefore, a possible way to improve this research would involve a probabilistic sampling process.

We do not know if in another social-cultural setting the results would be the same. Even so, in future studies, it would be recommendable to replicate these findings using new task based EI measuring instruments, such as the Mayer-Salovey-Caruso Emotional Intelligence Test-MSCEIT (Extremera et al., 2006; Mayer, Salovey, \& Caruso, 2002; Mayer, Salovey, Caruso, \& Sitarenios, 2003). However, the ultimate objective of this study was not so much assessing its actual execution, but determining the differences in the perceptual adjustment of parents regarding the SEI of their children and how it might influence the children's SEI based on gender. Furthermore, we should emphasize the validity of the self-report EI measurement against the execution measures (Austin, Saklofske, Huang, \& McKenney, 2004; Petrides \& Furnham, 2000, 2001, 2003; Saklofske, Austin, \& Minski, 2003) and in predicting vital variables like mental and physical health (Martins, Ramalho, \& Morin, 2010; Schutte, Malouff, Thorsteinsson, Bhullar, \& Rooke, 2007).

The results obtained will serve to expand scientific knowledge as prevention and intervention in the development of EI in the family.

\section{Conclusion}

From this study, we can conclude that parents perceive their children's emotion- 
al skills fittingly, being the mothers, in comparison to fathers, who show greater emotional adjustment in relation to SEI of their children. Possibly, these outcomes are the result of socialization of emotions differentiated in terms of gender, influenced by gender stereotypes. These differences are reflected in differences in the SEI of the sons and daughters of the sample, with greater self-reported emotional Attention of the daughters against most self-reported emotional Repair of sons, coinciding with some gender stereotypes. Males are expected to be strong and resilient while females are emotionally fragile (Petrides, Furnham, \& Martin, 2004). These results have important implications in the field of prevention and intervention in EI and health. Specifically, we refer to studies that show the relationship between self-reported EI and physical and mental health (Martins et al., 2010; Schutte et al., 2007). Finding all the variables that might be involved in the development of the SEI is essential to promote the optimal and balanced emotional development in the family. One of the highlighted results is to check the effect of parental beliefs about the children's SEI in the three factors of EI, directly through the father's PEI and indirectly through children's SEI. Promoting balanced gender stereotypes in IE with a more positive perception of both genders could help the development of factors less developed, favouring the development of all the factors that make up the EI. Indeed, studies in family androgyny show that the androgynous profiles are associated with greater IE (Guastello \& Guastello, 2003). The results show that the androgynous persons compared with instrumental and expressive, have higher levels of IE. From these results, it highlights the need to go beyond the approach of sex differences in IE and promoting identity referents less stereotypical by gender (Gartzia et al., 2012).

\section{References}

Argyle, M. (1990). The Psychology of Interpersonal Behaviour. Harmondsworth: Penguin.

Austin, E. J., Saklofske, D. H., Huang, S. H. S., \& McKenney, D. (2004). Measurement of Emotional Intelligence: Testing and Cross-Validating a Modified Version of Schutte et al. (1998) Measure. Personality and Individual Differences, 36, 555-562. https://doi.org/10.1016/S0191-8869(03)00114-4

Baron-Cohen, S. (2003). The Essential Difference: Men, Women and the Extreme Male Brain. London: Allen Lane.

Baron-Cohen, S. (2005). The Essential Difference: The Male and Female Brain. Phi Kappa Phi Forum, 85, 23-26.

https://search.proquest.com/docview/235184948?accountid=14513

Beyer, S. (1999). Gender Differences in the Accuracy of Grade Expectancies and Evaluations. Sex Roles, 41, 279-296. https://doi.org/10.1023/A:1018810430105

Brody, L. R., \& Hall, J. A. (1993). Gender and Emotion. In M. Lewis, \& J. Haviland (Eds.), Handbook of Emotions (pp. 447-461). New York, NY: Guilford Press.

Brown, J. R., \& Dunn, J. (1996). Continuities in Emotion Understanding from Three to Six Years. Child Development, 67, 789. https://doi.org/10.2307/1131861

https://search.proquest.com/docview/1634095771?accountid=14513 
Castro-Schilo, L., \& Kee, D. W. (2010). Gender Differences in the Relationship between Emotional Intelligence and Right Hemisphere Lateralization for Facial Processing. Brain and Cognition, 73, 62-67. https://doi.org/10.1016/j.bandc.2010.03.003

Chapman, B. P., \& Hayslip, B. Jr. (2006). Emotional Intelligence in Young and Middle Adulthood: Cross-Sectional Analysis of Latent Structure and Means. Psychology and Aging, 21, 411-418. https://doi.org/10.1037/0882-7974.21.2.411

Darling, N., \& Steinberg, L. (1993). Parenting Styles a Context: An Integrative Model. Psychological Bulletin, 113, 487-496. https://doi.org/10.1037/0033-2909.113.3.487

Denham, S. A. (1998). Emotional Development in Young Children. New York, NY: Guilford Press.

Denham, S. A., \& Grout, L. (1993). Socialization of Emotion: Pathway to Preschooler's Emotional and Social Competence. Journal of Nonverbal Behavior, 17, 205-227. https://doi.org/10.1007/BF00986120

Denham, S. A., Zoller, D., \& Couchoud, E. A. (1994). Socialization of Preschooler's Understanding of Emotion. Developmental Psychology, 30, 928-936.

https://doi.org/10.1037/0012-1649.30.6.928

Eisenberg, N. (1998). The Socialization of Socioemotional Competence. In D. Pushkar, W. M. Bukowski, A. E. Schwartzman, D. M. Stack, \& D. R. White (Eds.), Improving Competence across the Lifespan: Building Interventions Based on Theory and Research (pp. 59-78). New York, NY: Plenum Press.

Extremera, N., \& Fernández-Berrocal, P. (2002). Relation of Perceived Emotional Intelligence and Health-Related Quality of Life in Middle-Aged Women. Psychological Report, 91, 47-59. https://doi.org/10.2466/pr0.2002.91.1.47

Extremera, N., \& Fernández-Berrocal, P. (2005). Perceived Emotional Intelligence and Life Satisfaction: Predictive and Incremental Validity using the Trait Meta-Mood Scale. Personality and Individual Differences, 39, 937-948. https://doi.org/10.1016/j.paid.2005.03.012

Extremera, N., \& Fernández-Berrocal, P. (2006). Emotional Intelligence as Predictor of Mental, Social and Physical Health in University Students. The Spanish Journal of Psychology, 9, 45-51. https://doi.org/10.1017/S1138741600005965

Extremera, N., Fernández-Berrocal, P., \& Salovey, P. (2006). Spanish Version of the Mayer-Salovey-Caruso Emotional Intelligence Test (MSCEIT) Version 2.0: Reliabilities, Age, and Gender Differences. Psicothema, 18, 42-48. https://www.unioviedo.es/reunido/index.php/PST/article/view/8418

Fernández-Berrocal, P., Extremera, N., \& Ramos, N. (2004). Validity and Reliability of the Spanish Modified Version of the Trait Meta-Mood Scale. Psichological Reports, 94, 751-755. https://doi.org/10.2466/pr0.94.3.751-755

Fivush, R., Brotman, M. A., Buckner, J. P., \& Goodman, S. H. (2000). Gender Differences in Parent-Child Emotion Narratives. Sex Roles, 42, 233-253. https://doi.org/10.1023/A:1007091207068

Furnham, A., \& Bunclark (2006). Sex Differences in Parents' Estimations of Their Own and Their Children's Intelligence. Intelligence, 34, 1-14. https://doi.org/10.1016/j.intell.2005.05.005

Furnham, A., Rakow, T., \& Mak, T. (2002). The Determinants of Parents' Beliefs about Their Intelligence of Their Children: A Study from Hong Kong. International Journal of Psychology, 37, 343-352. https://doi.org/10.1080/00207590244000151

Gartzia, L., \& Lopez-Zafra, E. (2014). Gender Research in Spanish Psychology: An Overview for International Readers. Sex Roles, 79, 445-456. 
https://doi.org/10.1007/s11199-014-0380-x

Gartzia, L., \& López-Zafra, E. (2014). Perceptions of Gender Differences in Self-Report Measures of Emotional Intelligence. Sex Roles, 70, 479-495.

https://doi.org/10.1007/s11199-014-0368-6

Gartzia, L., Aritzeta, A., Balluerka, N., \& Barberá, E. (2012). Inteligencia Emocional y género: Más allá de las diferencias sexuales. Anales de psicología, 28, 567-575. https://doi.org/10.6018/analesps.28.2.124111

Goldenberg, I., Matheson, K., \& Mantler, J. (2006). The Assessment of Emotional Intelligence: A Comparison of Performance-Based and Self-Report Methodologies. Journal of Personality Assessment, 86, 33-45. https://doi.org/10.1207/s15327752jpa8601_05

Gottman, J. M. (1997). Meta-Emotion: How Families Communicate Emotionally. Mahwah, NJ: Lawrence Erlbaum Associates.

Guastello, D. D., \& Guastello, S. J. (2003). Androgyny, Gender Role Behavior, and Emotional Intelligence among College Students and Their Parents. Sex Roles, 49, 663-673. https://doi.org/10.1023/B:SERS.0000003136.67714.04

Gur, R. C., Gunning-Dixon, F., Bilker, W. B., \& Gur, R. E. (2002). Sex Differences in Temporo-Limbic and Frontal Brain Volumes of Healthy Adults. Cerebral Cortex, 12, 998-1003. https://doi.org/10.1093/cercor/12.9.998

Hargie, O., Saunders, C., \& Dickson, O. (1995). Social Skills in Interpersonal Communication. London: Routledge.

Jaušovec, N., \& Jaušovec, K. (2005). Sex Differences in Brain Activity Related to General and Emotional Intelligence. Brain and Cognition, 59, 277-286.

https://doi.org/10.1016/j.bandc.2005.08.001

Jones, S., Eisenberg, N., Fabes, R. A., \& MacKinnon, D. P. (2002). Parents' Reactions to Elementary School Children's Negative Emotions: Relations to Social and Emotional Functioning at School. Merrill-Palmer Quarterly, 48, 133-159.

https://doi.org/10.1353/mpq.2002.0007

Kafetsios, K. (2004). Attachment and Emotional Intelligence Abilities across the Life Course. Personality and Individual Differences, 37, 129-145.

https://doi.org/10.1016/j.paid.2003.08.006

Kirkcaldy, B., Noack, P., Furnham, A., \& Siefen, G. (2007). Parental Estimates of Their Own and Their Children's Intelligence. European Psychologist, 12, 173-180. https://doi.org/10.1027/1016-9040.12.3.173

Marsland, K. W., \& Likavec, S. C. (2003). Maternal Emotional Intelligence, Infant Attachment and Child Socio-Emotional Competence. In 15th Annual Meeting of the American Psychological Society. Atlanta, GA.

Martins, A., Ramalho, N., \& Morin, E. (2010). A Comprehensive Meta-Analysis of the Relationship between Emotional Intelligence and Health. Personality and Individual Differences, 49, 554-564. https://doi.org/10.1016/j.paid.2010.05.029

Matthews, G., Zeidner, M., \& Roberts, R. D. (2002). Development and Schooling of Emotional Intelligence. In G. Matthews, M. Zeidner, \& R. D. Roberts (Eds.), Emotional Intelligence. Science \& Myth (pp. 419-466). Boston: MIT Press.

Mayer, J. D., \& Salovey, P. (1997). What Is Emotional Intelligence? In P. Salovey, \& D. Sluyter (Eds.), Emotional Development and Emotional Intelligence: Implications for Educators (pp. 3-34). New York, NY: Basic Books.

Mayer, J. D., Salovey, P., \& Caruso, D. R. (2002). Mayer-Salovey-Caruso Emotional Intelligence Test (MSCEIT) Item Booklet. Toronto: MHS Publishers. 
Mayer, J. D., Salovey, P., \& Caruso, D. R. (2008). Emotional Intelligence: New Ability or Eclectic Traits? American psychologist, 63, 503-517. https://doi.org/10.1037/0003-066X.63.6.503

Mayer, J. D., Salovey, P., Caruso, D. R., \& Sitarenios, G. (2003). Measuring Emotional Intelligence with the MSCEIT V2.0. Emotion, 3, 97-105. https://doi.org/10.1037/1528-3542.3.1.97

McClure, E. B. (2000). A Meta-Analytic Review of Sex Differences in Facial Expression Processing and Their Development in Infants, Children, and Adolescents. Psychological Bulletin, 126, 424-453. https://doi.org/10.1037/0033-2909.126.3.424

Molero, D., Álvarez, F. O., \& de Ávila, M. R. M. R. (2010). Diferencias en la adquisición de competencias emocionales en función del género. Revista Electrónica de Investigación y Docencia (REID), No. 3. http://revistaselectronicas.ujaen.es/index.php/reid/article/view/1167

Morales, M. I. J., \& Zafra, E. L. (2008). El autoconcepto emocional como factor de riesgo emocional en estudiantes universitarios: Diferencias de género y edad. Boletín de Psicología, No. 93, 21-39.

Morris, A., Silk, J., Steinberg, L., Myers, S. S., \& Robinson, L. (2007). The Role of the Family Context in the Development of Emotion Regulation. Social Development, 16, 361-388. https://doi.org/10.1111/j.1467-9507.2007.00389.x

Palomera, R. (2009). El posible papel del contexto familiar en el desarrollo de la inteligencia Emocional. In P. Fernández-Berrocal, N. Extremera, R. Palomera, D. Ruíz-Aranda, J. M. Salguero, \& R. Cabello (Eds.), Avances en el estudio de la Inteligencia Emocional (pp. 457-461). Santander: Fundación Marcelino Botín.

Petrides, K. V., \& Furnham, A. (2000). Gender Differences in Measured and Self-Estimated Trait Emotional Intelligence. Sex Roles, 42, 449-461. https://search.proquest.com/docview/1308102771 ?accountid=14513 https://doi.org/10.1023/A:1007006523133

Petrides, K. V., \& Furnham, A. (2001). Trait Emotional Intelligence: Psychometric Investigation with Reference to Established Trait Taxonomies. European Journal of Personality, 15, 425-448. https://doi.org/10.1002/per.416

Petrides, K. V., \& Furnham, A. (2003). Trait Emotional Intelligence: Behavioural Validation in Two Studies of Emotion Recognition and Reactivity to Mood Induction. European Journal of Personality, 17, 39-57. https://doi.org/10.1002/per.466

Petrides, K. V., Furnham, A., \& Martin, G. N. (2004). Estimates of Emotional and Psychometric Intelligence: Evidence for Gender-Based Stereotypes. The Journal of Social Psychology, 144, 149-162. https://doi.org/10.3200/SOCP.144.2.149-162

Richaud, M. C. (2009). Influencia de modelado de los padres sobre el desarrolla del razonamiento prosocial en los/as niños/as. Interamerican Journal of Psychology, 43, 187-198.

http://pepsic.bvsalud.org/scielo.php?script=sci_arttext\&pid=S0034-9690200900010002 1

Rosenthal, R., Hall, J. A., DiMatteo, M. R., Rogers, P. L., \& Archer, D. (1979). Sensitivity to Nonverbal Communication: The PONS Test. Baltimore: Johns Hopkins University Press.

Rothbart, M. K., \& Derryberry, D. (1981). Development of Individual Difference in Temperament. In M. E. Lamb, \& A. L. Brown (Eds.), Advances in Developmental Psychology (pp. 37-86). Hillsdale, NJ: Lawrence Erlbaum Associates.

Rubio, C. M., \& Sánchez-Núñez, T. (2013). Inteligencia Emocional autoinformada en 
hijos únicos e hijos primogénitos y ajuste perceptivo de los progenitores. Ansiedad y Estrés, 19, 235-242.

https://search.proquest.com/docview/1499095379? accountid=14513

Saklofske, D. H., Austin, E. J., \& Minski, P. S. (2003). Factor Structure and Validity of a Trait Emotional Intelligence Measure. Personality and Individual Differences, 34, 707-721. https://doi.org/10.1016/S0191-8869(02)00056-9

Salovey, P., Bedell, B., Detweiler, J. B., \& Mayer, J. D. (2000). Current Directions in Emotional Intelligence Research. In M. Lewis, \& J. M. Haviland-Jones (Eds.), Handbook of Emotions (2nd ed.). New York, NY: Guilford Press.

Salovey, P., Mayer, J. D., Goldman, S. L., Turvey, C., \& Palfai, T. P. (1995). Emotional Attention, Clarity, and Repair: Exploring Emotional Intelligence using Trait Meta-Mood Scale. In J. W. Pennebaker (Ed.), Emotion, Disclosure and Health (pp. 125-154). Washington DC: APA.

Sánchez-Núñez, M. T., Fernández-Berrocal, P., \& Latorre, J. M. (2013). Assessment of Emotional Intelligence in the Family: Influences between Parents and Children on Their Own Perception and That of Others. The Family Journal, 21, 44-52.

Sánchez-Núñez, M. T., Fernández-Berrocal, P., Montanes, J., \& Latorre, J. M. (2008). Does Emotional Intelligence Depend on Gender? The Socialization of Emotional Competencies in Men and Women and ItsImplications. Electronic Journal of Research in Educational Psychology, 6, 455-474.

http://repositorio.ual.es/bitstream/handle/10835/540/Art_15_253_eng.pdf?sequence=1

Schutte, N. S., Malouff, J. M., Thorsteinsson, E. B., Bhullar, N., \& Rooke, S. E. (2007). A Meta-Analytic Investigation of the Relationship between Emotional Intelligence and Health. Personality and Individual Differences, 42, 921-933. https://doi.org/10.1016/j.paid.2006.09.003

Shi, J., \& Wang, L. (2007). Validation of Emotional Intelligence Scale in Chinese University Students. Personality and Individual Differences, 43, 377-387.

https://doi.org/10.1016/j.paid.2006.12.012

Shin, L. T. (2011). Gender Differences in Emotional Intelligence: Are You as Smart as You Think Emotionally? B.Sc. Honors Thesis, Selangor: Universiti Tunku Abdul Rahman (UTAR). http://eprints.utar.edu.my/276/1/PY-2011-0802449.pdf

Shipman, K. L., \& Zeman, K. (1999). Emotion Understanding: A Comparison of Physically Maltreating and Nonmaltreating Mother-Child Dyads. Journal of Clinical Child Psychology, 28, 407-417. https://doi.org/10.1207/S15374424jccp280313

Sunew, E. Y. (2004). Emotional Intelligence in School-Aged Children: Relations to Early Maternal Depression and Cognitive Functioning. Dissertation Abstracts International: Section B: The Sciences and Engineering, 65, 2116B.

http://elibrary.ru/item.asp?id=8868729

Thompson, R. A. (1998). Emotional Competence and the Development of Self. Psychological Inquiry, 9, 308-309. https://doi.org/10.1207/s15327965pli0904_14

Van Rooy, D. L., Alonso, A., \& Viswesvaran, C. (2005). Group Differences in Emotional Intelligence Scores: Theoretical and Practical Implications. Personality and Individual Differences, 38, 689-700. https://doi.org/10.1016/j.paid.2004.05.023

Zeidner, M., Matthews, G., Roberts, R. D., \& MacCann, C. (2003). Development of Emotional Intelligence: Towards a Multi-Level Investment Model. Human Development, 46, 69-96. https://doi.org/10.1159/000068580 